\title{
PELATIHAN PENILAIAN KINERJA PENDIDIK BAGI GURU DKI JAKARTA
}

\author{
Merry Lapasau $^{1)}$, Soeparlan Kasyadi ${ }^{2)}$, Virgana Virgana ${ }^{3)}$ \\ ${ }^{1)}$ Program Studi Pendidikan Bahasa Inggris, Fakultas Pascasarjana, Universitas Indraprasta PGRI \\ ${ }^{2}$ Program Studi Pendidikan IPS, Fakultas Pascasarjana, Universitas Indraprasta PGRI \\ ${ }^{3)}$ Program Studi Pendidikan MIPA, Fakultas Pascasarjana, Universitas Indraprasta PGRI
}

\begin{abstract}
Abstrak
Dalam upaya mengembangkan diri sesuai tuntutan profesi guru, guru diharapkan dapat tetap menambah pengetahuan walaupun dalam keadaan keterbatasan seperti di masa wabah Covid-19 ini, antara lain dengan mengikuti seminar yang dilaksanakan secara daring. Oleh karena itu, kami tim abdimas dari universitas Indraprasta mengadakan seminar daring mengenai penilaian pendidik untuk para guru. Seminar ini bertujuan untuk mengakomodasi guru-guru dari berbagai provinsi di Indonesia terutama dari DKI Jakarta untuk lebih memahami masalah penilaian kinerja guru. Seminar dilakukan melalui media google meet sebagai bagian dari mematuhi protokol kesehatan di masa wabah Covid-19 dan dilaksanakan pada tanggal 10 Juni 2020. Dari hasil pelaksanaan abdimas ini dapat disimpulkan bahwa seminar daring yang berkaitan dengan profesi guru sangatlah dibutuhkan. Guru menganggap perlu diadakan kembali seminar dan latihan lainnya yang dapat menunjang profesi mereka.
\end{abstract}

Kata kunci: Penilaian kinerja guru, seminar daring, Covid-19

\begin{abstract}
Teachers are expected to be able to increase their knowledge in an effort to develop themselves according to the demands of the teaching profession even in limited circumstances such as during the Covid-19 outbreak. In order to keep up with the development in these days, they can attend online seminars. Therefore, we, the community service team from Indraprasta University, held an online seminar on teacher assessment for teachers. The seminar was conducted through google meet as a part of complying with health protocols during the Covid-19 outbreak and was held on June 10, 2020. This seminar accommodates teachers from various provinces in Indonesia, especially from DKI Jakarta. From the results of the implementation of this community service it can be concluded that the need for online seminars related to the teacher profession is big. Teachers consider the need for re-held seminars and other exercises that can support their profession.
\end{abstract}

Keywords: Teacher assessment, online seminar, Covid-19

Corresponding author: Merry Lapasau, mlapasau@gmail.com, Jakarta, Indonesia

This work is licensed under a CC-BY-NC

\section{PENDAHULUAN}

Di masa wabah Covid-19 ini, kita dituntut untuk tetap berkarya dan berprestasi di bidang yang kita tekuni masing-masing. Sesuai dengan pendapat Kasyadi et.al., (2020) yang menyatakan bahwa dengan masifnya penyebaran pandemi korona atau Covid-19 
secara global, pendidikan di Indonesia menghadapi tantangan baru dalam melaksanakan kegiatan pembelajaran dan pendidikan. Kegiatan pembelajaran dan pendidikan secara umum dilaksanakan dengan sistem jarak jauh atau yang dikenal dengan daring. Dalam masa ini, guru diharapkan dapat beradaptasi dengan keadaan yang ada dengan mencari solusi yang terbaik untuk tetap menghasilkan kinerja profesional dan membangun kinerja diri. Menurut Mitrani (dalam Faizah, 2019) kinerja dapat dipahami sejauh mana seseorang telah memainkan perannya dalam melaksanakan strategi organisasi, baik dalam mencapai sasaran-sasaran khusus yang berhubungan dengan peranan perseorangan, dan atau dengan memperlihatkan kompetensi-kompetensi yang dinyatakan relevan bagi organisasi apakah dalam suatu peranan tertentu, atau secara lebih umum.

Penilaian kinerja guru dilakukan sesuai dengan Peraturan Menteri Negara Pendayagunaan Aparatur Negara dan Reformasi Birokrasi Nomor 16 tahun 2009 tanggal: 10 November 2009, yang memuat tentang rincian kegiatan guru dan angka kreditnya. Kegiatan yang harus dilaksanakan guru berdasarkan peraturan tersebut, yaitu: 1) Mengikuti pendidikan dan memperoleh gelar/ijazah/akta, 2) Mengikuti pelatihan prajabatan, 3) Melaksanakan proses pembelajaran, 4) Melaksanakan proses bimbingan, 5) Melaksanakan tugas lain yang relevan dengan fungsi sekolah/madrasah, 6) Melaksanakan pengembangan diri, 7) Melaksanakan publikasi ilmiah, dan 8) Melaksanakan karya inovatif. Oleh karena itu, untuk memenuhi kinerja guru tersebut, seorang guru sebagai tenaga pendidik diharapkan untuk terus menerus meningkatkan kemampuan profesionalnya, seiring dengan perkembangan jaman, ilmu pengetahuan dan teknologi, serta kebutuhan masyarakat saat ini yang sudah semakin luas dengan terbukanya akses ilmu pengetahuan dengan mudah. Tujuan penilaian kinerja pendidik seperti yang terlampir pada Permenneg PAN \& RB No. 16/2009 adalah sebagai berikut: 1. Penilaian kinerja pendidik menjamin bahwa pendidik melaksanakan pekerjaannya secara profesional, 2. Penilaian kinerja pendidik menjamin bahwa layanan pendidikan yang diberikan oleh pendidik adalah berkualitas.

Untuk mencapai semua kinerja guru di atas, diperlukan kesadaran guru untuk terus melatih dan memperbaiki diri, salah satunya dengan mengikuti berbagai kegiatan yang bermanfaat dan sesuai bidangnya untuk pengembangan diri. Menurut Jamma (2013), guru harus benar-benar mengerti tugasnya karena keberhasilan pelaksanaan pembelajaran di sekolah juga sangat ditentukan salah satunya oleh kinerja guru. Lebih jauh Syafriadi (2015) menjelaskan bahwa peningkatan mutu pendidikan dan sumber daya manusia di sekolah - dalam hal ini guru- diperlukan secara individu atau kolaboratif untuk memperbaiki kualitas pendidikan dan pembelajaran.

Selama masa wabah Covid-19 ini, kita semua dituntut untuk mematuhi protokol kesehatan, yaitu diantaranya dengan menjaga jarak dengan orang lain. Di masa ini, guru diharapkan dapat mencari solusi agar tetap dapat menghadiri seminar pendidikan yang berguna bagi pengembangan dirinya.

Kinerja pendidik harus tetap dipertahankan dengan memperhatikan protokol kesehatan yang sudah diatur pemerintah dan dinas kesehatan. Penilaian kinerja pendidik berguna antara lain: 1) Sebagai evaluasi diri bagi pendidik untuk mengembangkan potensi dan karirnya, 2) Sebagai acuan bagi sekolah untuk merencanakan Pengembangan Keprofesian Berkelanjutan (PKB), dan 3) Sebagai dasar dalam memberikan nilai prestasi kerja pendidik dalam rangka pengembangan karier pendidik sesuai Permennegpan \& RB No.16/2009. 
Dalam upaya mengembangkan diri sesuai tuntutan profesi guru, maka guru dapat tetap menambah pengetahuan walaupun dalam keadaan keterbatasan seperti di masa wabah Covid-19 ini antara lain dengan cara mengikuti seminar yang dilaksanakan secara daring. Aqib dan Rohmanto (dalam Rohmah, 2016) menjelaskan bahwa profesionalisme ditunjukkan oleh lima unjuk kerja sebagai berikut: a) Keinginan untuk selalu menampilkan perilaku yang mendekati standar ideal, b) Meningkatkan dan memelihara citra profesi, 3) Keinginan untuk senantiasa mengejar kesempatan pengembangan professional yang dapat meningkatkan dan memperbaiki kualitas pengetahuan dan keterampilan, 4) Mengejar kualitas dan cita-cita dalam profesi, 5) Memiliki kebanggaan terhadap profesinya.

Berdasarkan uraian di atas, Tim abdimas dari UNINDRA mencoba memberi solusi dengan mengadakan seminar daring sehari yang dilakukan untuk memberi informasi lengkap kepada para guru yang tidak terbatas lokasi asalnya tentang penilaian kinerja guru dengan judul "Pelatihan Penilaian Kinerja Pendidik Bagi Guru".

Untuk lebih mengarahkan kegiatan ini, tim pelaksana menyusun tujuan kegiatan sebagai berikut: 1) Memberikan pengetahuan dan wawasan mengenai penilaian kinerja pendidik untuk mengukur kompetensi yang dimiliki pendidik, Pengembangan Keprofesian Berkelanjutan pendidik untuk memelihara dan meningkatkan kompetensi pendidik yang berdampak pada kenaikan angka kredit. 2) Memberikan contoh konkret dan latihan untuk menghitung nilai per indikator pendidik agar para guru dapat menghitung sendiri angka kredit masing-masing sesuai dengan aturan yang berlaku.

\section{METODE PELAKSANAAN}

Kegiatan pengabdian masyarakat ini secara umum bertujuan untuk meningkatkan profesionalisme guru-guru melalui seminar daring mengenai penilaian kinerja pendidik dan dilaksanakan pada tanggal 10 Juni 2020. Adapun khalayak sasaran dalam kegiatan pengabdian ini adalah guru-guru di sekolah menengah yang berasal dari berbagai sekolah yang mempunyai akses internet. Seminar ini tidak dipungut bayaran, para guru hanya perlu mendaftar dan mereka juga mendapat sertifikat setelah mengikuti kegiatan seminar daring ini. Kegiatan pengabdian masyarakat ini dilakukan dengan metode ceramah dalam bentuk seminar daring menggunakan media google meet yang diikuti sekitar 150 guru. Narasumber memberikan paparannya mengenai bagaimana seluk beluk penilaian kinerja pendidik dan dilengkapi dengan contoh perhitungan angka kredit guru. Acara seminar daring diakhiri dengan kegiatan tanya jawab. Secara keseluruhan, acara berlangsung kurang lebih 120 menit.

\section{HASIL DAN PEMBAHASAN}

Seperti yang telah dikemukakan sebelumnya, kegiatan pengabdian masyarakat kali ini berbentuk seminar daring. Acara ini dilakukan guna membantu guru-guru agar mempunyai pengetahuan yang menyeluruh tentang Pengembangan Keprofesian Berkelanjutan sebagai usaha pengembangan kompetensi pendidik yang dilaksanakan sesuai dengan kebutuhan, secara bertahap, dan berkelanjutan untuk meningkatkan 
profesionalitas pendidik. Sebagaimana pelaksanaan sebuah kegiatan pada umumnya, pengabdian masyarakat ini dilaksanakan dalam tiga tahap, yaitu:

1. tahap persiapan

2. tahap pelaksanaan

3. tahap evaluasi

Tim abdimas Unindra sebenarnya telah menyiapkan persiapan yang berbeda, yaitu tim akan melakukan survei ke sekolah. Namun, karena diberlakukan pembatasan ruang gerak akibat pandemi Covid-19, maka kami memutuskan tidak melakukan survei. Selanjutnya kami menyusun rancangan kegiatan yang akan dilakukan, serta menyiapkan bahan-bahan yang akan dijadikan materi presentasi melalui google meet.

Selanjutnya adalah tahap pelaksanaan. Pelatihan ini dimulai dengan penyampaian materi oleh Dr. Soeparlan Kasyadi yang memaparkan dengan jelas mengenai penilaian kinerja pendidik mulai dari tujuan penilaian kinerja pendidik, alur pembinaan dan pengembangan profesi pendidik, dasar hukum, manfaat, dan terakhir pelaksanaan penilaian kinerja di sekolah.Tim menyampaikan materi tentang Penilaian Kinerja Pendidik melalui seminar daring yang diselenggarakan bersama dengan tim kedua dengan pemateri Dr. Virgana yang menyampaikan materi tentang Penulisan Artikel Ilmiah berbasis PTK. Materi kedua ini juga sangat bermanfaat bagi para guru, sebab guru juga dapat melakukan pengembangan diri dengan cara menulis karya ilmiah atas hasil penelitian atau gagasan ilmu di bidang pendidikan formal. Menurut Prayitno et.al (dalam Lapasau et al., 2020), makalah ilmiah adalah suatu makalah yang memuat dan mengkaji suatu masalah tertentu dengan menggunakan kaidah-kaidah keilmuan. Salah satu yang persyaratan bagi guru untuk dapat naik ke golongan IVB adalah menulis makalah ilmiah.

Terakhir adalah tahap evaluasi. Tim abdimas melaksanakan evaluasi dengan memberikan pertanyaan yang dijawab peserta melalui google form tentang kepuasan mereka terhadap seminar yang telah mereka ikuti. Berdasarkan hasil survei singkat tersebut, diketahui bahwa kebutuhan akan seminar daring yang berkaitan dengan profesi guru sangatlah dibutuhkan. Guru menganggap perlu adanya diadakan kembali seminar dan latihan lainnya yang dapat menunjang profesi mereka. Kegiatan seminar secara daring juga dianggap tepat karena sesuai dengan keadaan saat ini.

Kegiatan abdimas semester genap 2019-2020 tidak dilaksanakan di tempat mitra tetapi dilaksanakan dalam bentuk seminar daring di Universitas Indraprasta PGRI terkait pembatasan dalam masa wabah Covid-19. Berikut poster dan sebagian dari materi kegiatan seminar kami:

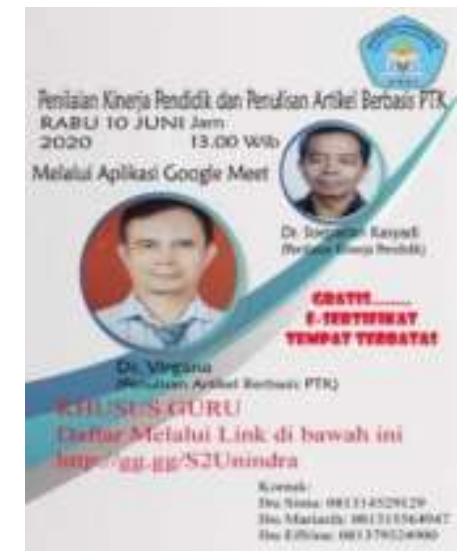

Gambar 1. Poster kegiatan abdimas

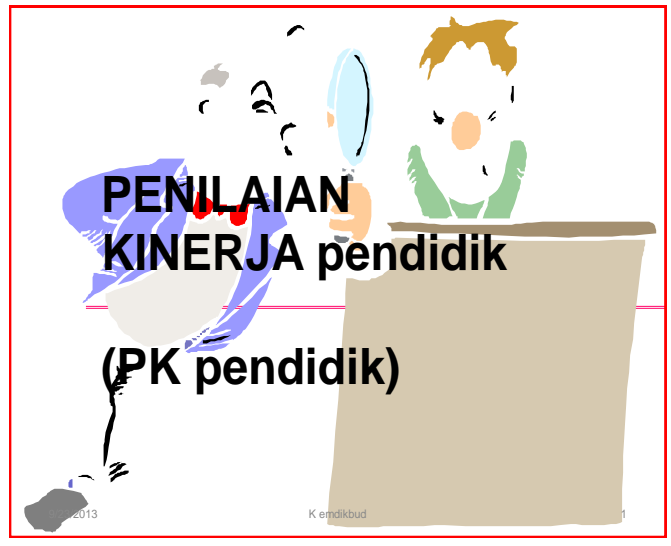

Gambar 2 Judul materi abdimas 


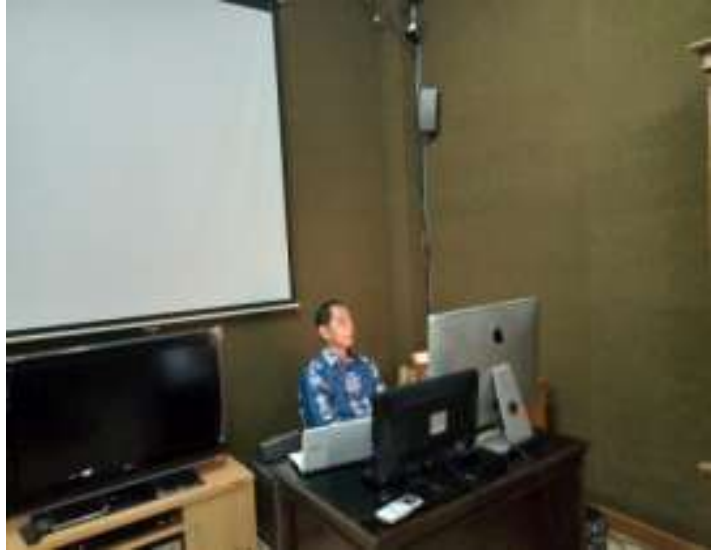

Gambar 3 Kegiatan abdimas oleh Narasumber

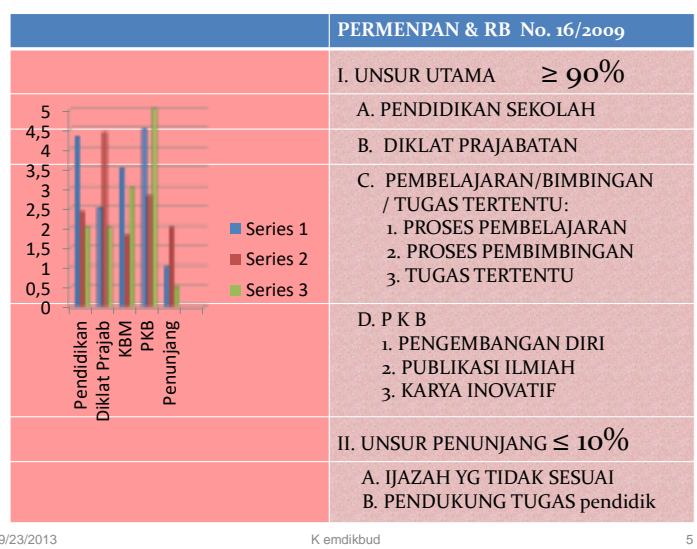

Gambar 5 Materi abdimas (Permenpan \&RB No.16/2009)

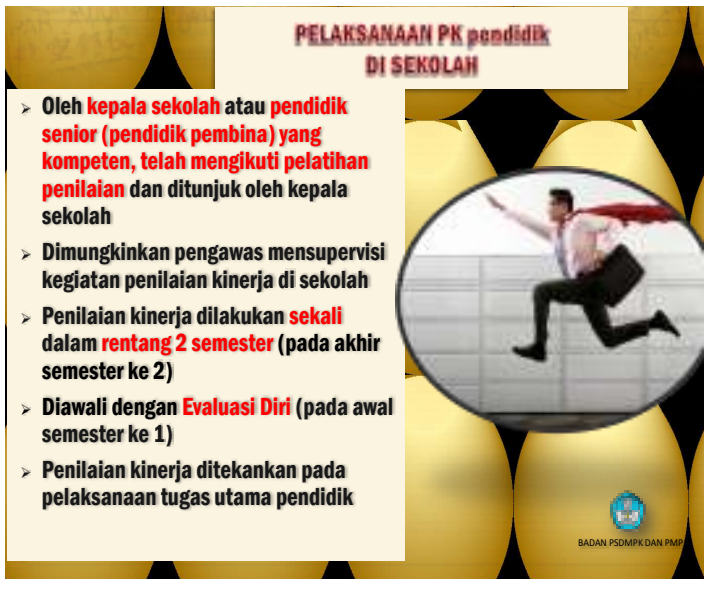

Gambar 7 Materi abdimas (Pelaksanaan PK Pendidik-1)

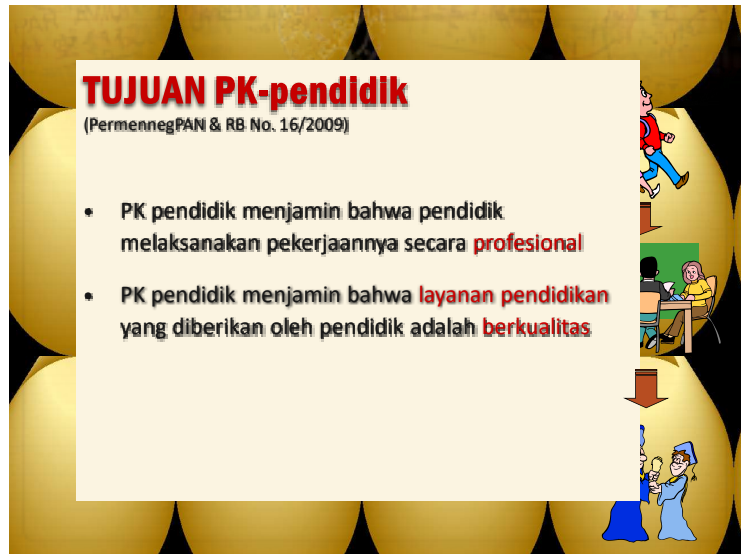

Gambar 4 Materi abdimas (Tujuan PK-Pendidik)

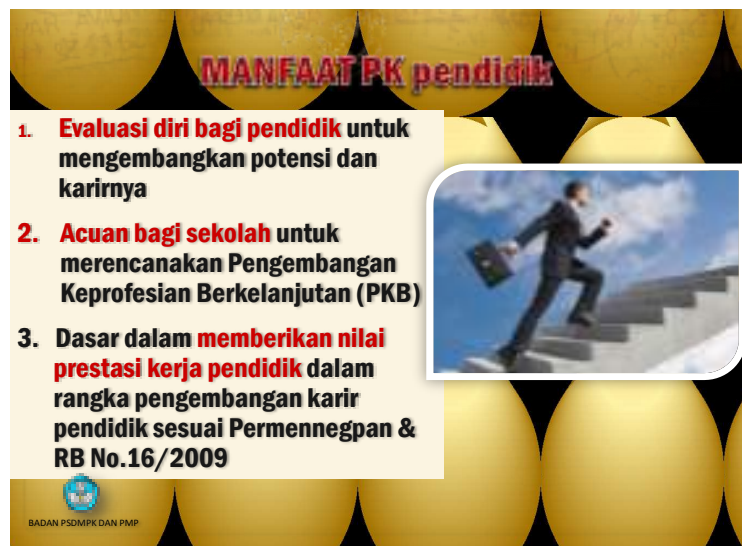

Gambar 6 Materi abdimas (manfaat PK Pendidik)

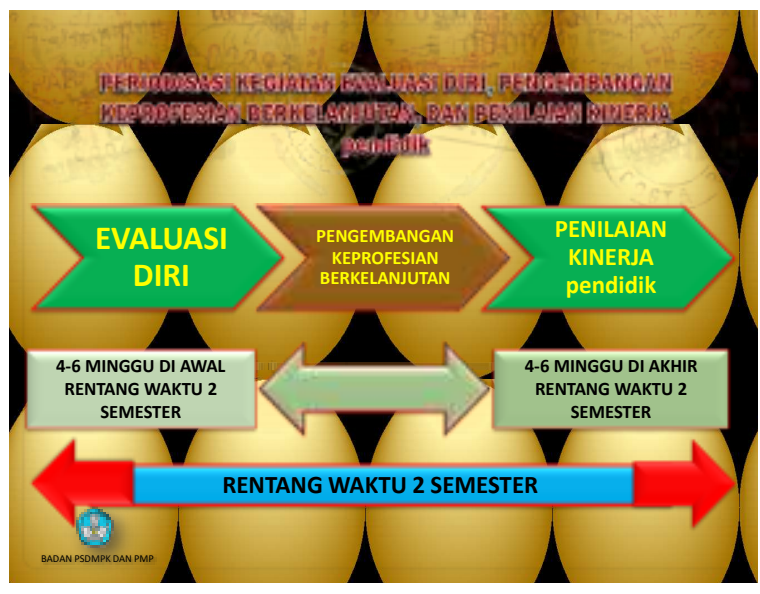

Gambar 8 Materi abdimas

(Pelaksanaan PK Pendidik-2)

\section{SIMPULAN}

Kegiatan seminar daring bagi guru-guru di DKI Jakarta dan sekitarnya telah memberi pengaruh positif pada para guru dan pihak sekolah. Dari hasil survei singkat 
setelah pelaksanaan abdimas dapat diketahui bahwa seminar ini sangat berguna, di samping untuk meningkatkan wawasan dan keterampilan guru, seminar ini juga memberikan dorongan bagi mereka untuk turut serta dalam uji kompetensi guna meningkatkan kinerja profesi mereka.

Lebih jauh, kegiatan pengabdian masyarakat ini memberikan jalan keluar positif bagi permasalahan para guru untuk terus menambah pengetahuan dan meningkatkan kinerja profesi di masa wabah Covid-19. Hal-hal positif yang diperoleh dari kegiatan pelatihan ini dapat dilihat dari antusiasme peserta dalam mengikuti kegiatan ini. Peserta yang awalnya diperkirakan hanya akan berjumlah 100-150 orang, ternyata pada saat pendaftaran hari pertama sudah melampaui kapasitas, sehingga tim abdimas harus membatasi jumlah peserta berdasarkan kuota yang tersedia.

Abdimas dilaksanakan dengan tertib pada tanggal 10 Juni pukul 13:00-15:00 dan diikuti kurang lebih 150 guru yang mendengarkan penjelasan dari tim pelaksana dengan seksama. Kegiatan abdimas dibagi dalam dua sesi dan narasumber memberikan kesempatan kepada peserta untuk menanyakan hal-hal yang belum jelas. Kegiatan ini ditutup dengan survei yang berisi masukan dari peserta terhadap kegiatan abdimas ini.

\section{DAFTAR PUSTAKA}

Faiza, Umi. (2019). Evaluasi Kinerja Pendidik dan Tenaga Kependidikan dan Proses Pembelajaran Pendidikan Islam di Indonesia. Al Fikri. Jurnal Studi dan Penelitian Pendidikan Islam. 2 (2), 44-54.

Jamma, Hubban. (2013). Hubungan Gaya Kepemimpinan dan Kinerja dengan Etos Kerja Guru Sekolah Dasar di Kota Padang Panjang. Jurnal al-Fikrah, 1(2), 49159.

Kasyadi, S. et al (2020). Enhancing Learning Outcome in Integral through Online Teaching based during COVID-19 Pandemic. Journal of Physics: Conference Series 1663 (2020) 012059. 1-6. Doi:10.1088/1742-6596/1663/1/012059.

Lapasau, M. et al (2020). Pelatihan Pemanfaatan Sumber Pustaka dalam Menunjang Penulisan Makalah Ilmiah Bagi Guru SMKN 10 Tangerang. Jurnal Cemerlang: Pengabdian pada Masyarakat. 2 (2). 133 - 147. Doi: https://doi.org/ 10.31540/ jpm.v2i2.908.

Rohmah, Wafrotur. (2016). Upaya Meningkatkan Pengembangan Keprofesian Berkelanjutan Dalam Peningkatan Profesionalisme Guru. Prosiding Seminar Nasional Pendidikan (SNP) 2016, ISSN: 25034855. 10-21.

Syafriadi, M. (2015). Kinerja Guru Sertifikasi Pada Madrasah Aliyah Swasta (MAS) Plus Padang Ganting Kabupaten Tanah Datar. Jurnal al-Fikrah. III (1) 63-75. 